\title{
Automotive industry: trends in the implementation of modern corporate strategies
}

\author{
Oleg Zhilkin*, and Svetlana Kiryukhina \\ Peoples' friendship university of Russia, Miklukho-Maklaya str.6, 117198 Moscow, Russia
}

\begin{abstract}
The article attempts to identify new directions for the strategic development of automotive enterprises, taking into account current trends, using the example of both the largest German concerns, such as BMW Group and Volkswagen AG, and actively developing Chinese manufacturers - BAIC, Chery, Geely, JAC, JAV. The emphasis is on the production of hybrid and electric vehicles. Special attention is paid to the prospects for the development of the Russian segment of the production of cars with hybrid and electric drives and identifying problems that hinder its advanced development and the reasons that hinder the expansion of the segment of using cars with hybrid and electric drives, both Russian and imported
\end{abstract}

\section{Introduction}

Corporate strategy acts as the main tool for strategic management and represents a preplanned reaction of the company to changes in the external environment, the trajectory of its behavior, developed to achieve the set goals. Analysis of foreign experience in the formation of corporate strategies showed that the main attention in their development is paid to four aspects of business strategy:

- selection of product markets and investment volumes;

- determination of possible volumes of production and sales of products;

- identification of assets and competencies necessary to ensure sustainable competitive advantage;

- development of functional strategies.

The main component of developing a strategy for commodity-market investment is the choice of a business area and an analysis of the dynamic processes occurring within it.

When defining investment sectors, the corporation's management primarily proceeds from several circumstances:

- out of the need to gain a foothold in those commodity markets where there is a steady growth in sales;

- from accelerating the introduction of the most promising innovative products into serial production;

- from the tasks of continuous development of their own research and development work.

To ensure a sustainable competitive advantage, an economically sound choice of strategic asset allocation is required, i.e. resources that surpass in their characteristics the resources of

${ }^{*}$ Corresponding author: zhilkin_on@pfur.ru 
competitors, and strategic competencies - strategically important for the corporation areas of activity, the development of which is based on special knowledge or competencies. Consequently, in the process of developing a corporate strategy, it is necessary to provide for the costs of creating and maintaining strategic assets and competencies designed to provide the appropriate technical capabilities for the production of competitive products.

The final stage in the formation of a corporation's business strategy is the development of functional strategies and programs. Typically, functional strategies cover the areas of production, distribution, communications, informatization, etc.

Along with the global market strategy, a market segmentation strategy is being developed. Functional strategies are complemented by specific programs (quality, customer relations, branding, etc.).

The main approaches to the development of an organization's strategy boil down to the fact that a strategy is a combination of the results of theoretical analysis and the intuition of developers, which, first of all, should be the subjects, who then detail and implement the strategy. It is also important that a strategy can never be thought out and calculated to the end, and its adjustment as external and internal conditions change is a necessary procedure.

Based on the foregoing, it should be emphasized that there is no universal method of developing a strategy suitable for all occasions.

\section{Literature review}

Many scientists were involved in the formation of corporate strategies, however, the generally recognized leaders are K. Andrews (Andrews KR, 1971), M. Porter (Porter M., 2013), G. Hamel and K. Prahalad (Prahalad K.K., Hamel G., 2011).

In particular, the Association for the Development of Electric, Unmanned and Connected Transport and Infrastructure and the Analytical Agency "AUTOSTAT" are engaged in analyzing the trends of what is happening in the modern car production market.

\section{Theoretical foundations for the formation of corporate strategies}

Harvard Business School is considered to be the leader in the development of procedures for the formation of strategies. K. Andrews (Andrews K. R., 1971), M. Porter (Porter M., 2013), G. Hamel and K. Prahalad (Prahalad K.K., Hamel G., 2011) developed in the XX century. the main approaches to the formation of such strategies as "Economic Strategy", "Business Strategy" and "Leadership Strategy".

K. Andrews proposed a strategy based on the correspondence between the existing market opportunities and the organization's capabilities at a given level of risk. Approaches to developing business strategy based on the competitive position of the organization and the competitive strategies themselves were developed by Porter, and the concept of core competencies belongs to G. Hamel and K. Prahalad. Analysis of the model of five forces of competition makes it possible to determine the strengths and weaknesses of the organization in the market and in the areas, strategic changes in which, in accordance with the forecast, can give maximum results for business development.

The different state of the external and internal environment of organizations explains the diversity of the organizations themselves and their actual state.

The multifactorial nature of the parameters that determine the position of each organization does not allow to systematize these parameters and formalize the process of developing an image of the existing and desired state of the organization. 
Practice shows that the best results are achieved by organizations that, when choosing goods and services, not only focus on meeting the needs of customers, but can also outstrip the needs of consumers or, even better, form these requests. For example, the need for mobile phone communication has been generated by mobile telesystem companies. There is a relationship between the amount of demand and the price of a commodity, which is called the law of demand. The following categories of demand should be considered:

- primary demand, which is understood as the minimum demand determined by the needs of the population (basic food products, consumer goods, etc.);

- secondary demand - needs of a higher order, which appear with a time lag in relation to the primary demand (delicacies, etc.);

- realized demand, which is accompanied by the actual purchase of goods;

- rush demand caused by the desire of more and more layers of consumers to make a purchase of goods purchased by other buyers;

- unsatisfied (or deferred) demand caused by the lack of the required product on sale;

- emerging demand, which is focused on new products that are being prepared for release.

However, knowing the demand does not yet guarantee success in the market. It is necessary to structure the process of transforming resources into finished products in such a way that the value of resources is maximally preserved and increased due to the synergy effect. Therefore, it is required to analyze the potential of the organization in terms of the ability to provide effective processes within the organization itself. As a result, it is not only the stage of the product life cycle that matters, but also the life cycle stage at which the organization itself is located.

An important condition for the formation of an innovative strategy is to take into account, through a formalized toolkit, the potential opportunities and prospects for the use of certain innovations in connection with the development of the internal and external environment of the enterprise. The lack of such accounting may lead in the future to technological or market inadequacy of currently relevant innovative products and services.

\section{The main strategic directions for the development of automobile transport}

The main strategic directions for the development of transport from a historical point of view, cars with internal combustion engines appeared later than electric cars. However, due to the lack of sufficiently developed technologies for storing electricity, the large weight of batteries, which reduced the payload of the car and high operating costs, from an economic point of view, cars with internal combustion engines turned out to be more practical.

However, in modern conditions, when it is widely said that the reserves of explored deposits of natural resources from which fuel for cars with internal combustion engines is produced is steadily decreasing, that oil and oil products have recently become an instrument in the "games" of big politics, that cars with internal combustion engines are one of the main sources of environmental pollution, and the level of development of modern technologies makes it possible to create cars on alternative traction with comparable costs, the world leaders of car manufacturers increasingly began to pay attention to the creation of cars, the movement of which is provided by electrical devices.

Fig. 1 shows the dynamics of sales of electric vehicles and plug-in hybrids in the world for 2017-2019. The data presented clearly shows that there is a stable trend of growth in demand for cars with electric and hybrid drive, and in 2018 the growth is taking on an exponential nature, which suggests that the demand for cars with electric and hybrid drive will continue to grow steadily in the future. 


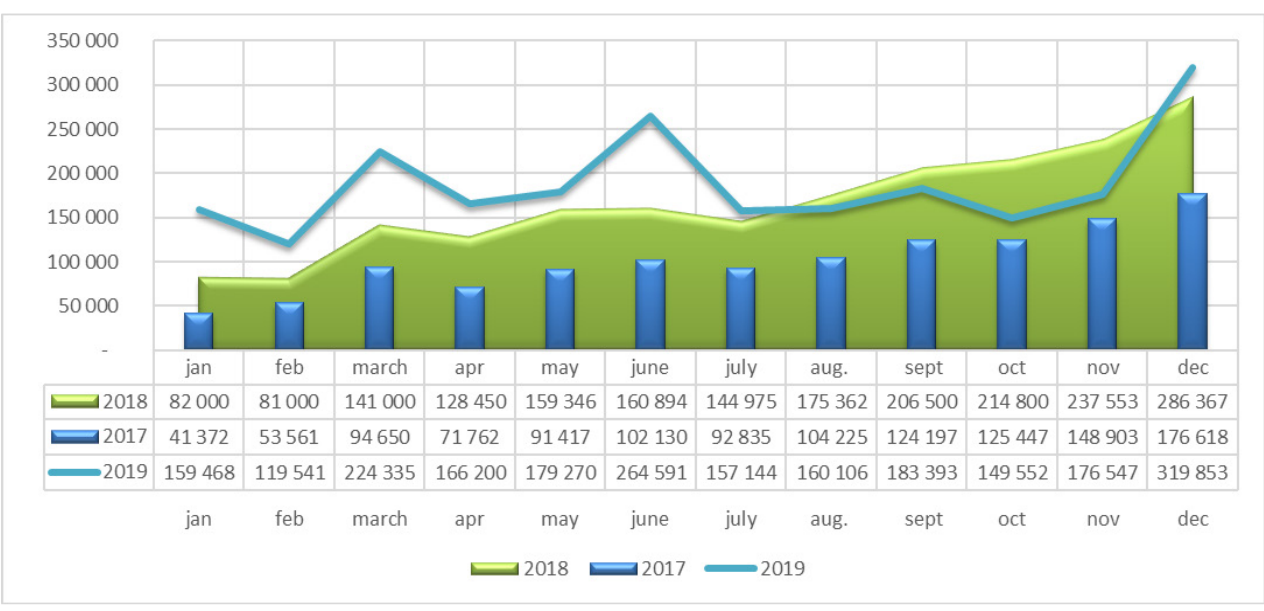

Fig. 1. Dynamics of sales of electric vehicles and plug-in hybrids in the world [5].

Figure 2 shows the comparative dynamics of sales of electric cars and cars with internal combustion engines in the world for 2012-2020

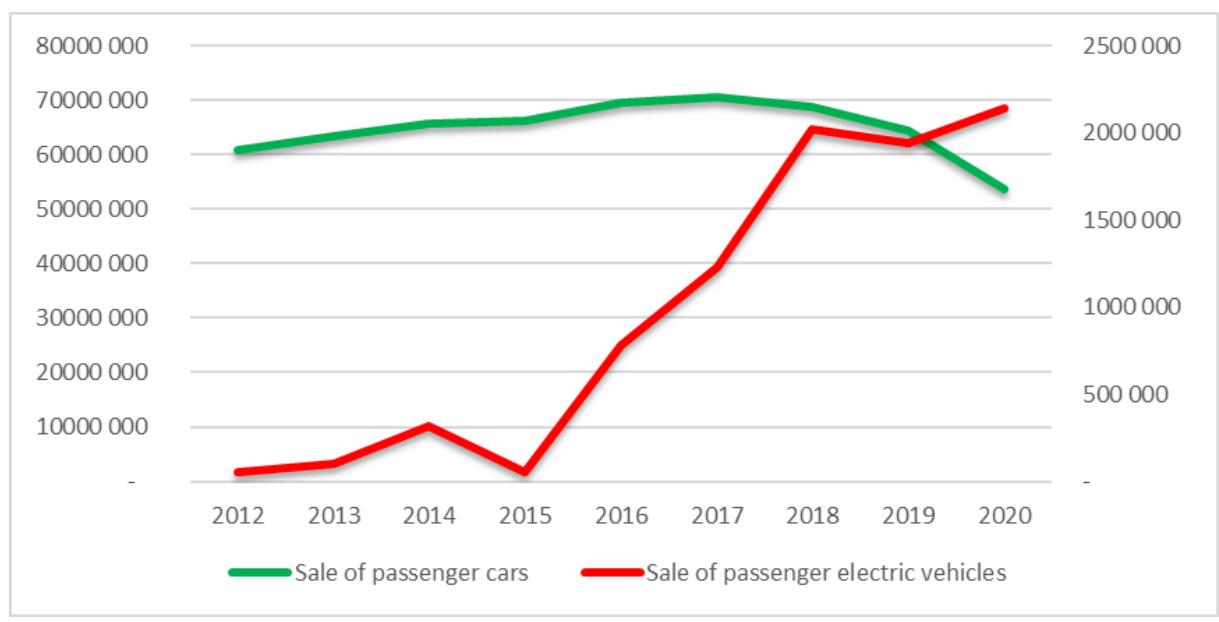

Fig. 2. Comparative dynamics of sales of passenger cars and passenger electric vehicles for 2012-2020

Analysis of data on the dynamics of sales of electric vehicles and rechargeable hybrids in the world in 2017-2019. (Table 1) shows a steady increase in demand for cars with engines that do not use refined petroleum products.

Table 1. Sales of electric vehicles and plug-in hybrids in the world in 2017-2019. (thousand pcs).

\begin{tabular}{|c|c|c|c|c|c|c|c|c|c|c|c|c|c|}
\hline $\begin{array}{c}\text { Mont } \\
\text { h / } \\
\text { year }\end{array}$ & 01 & 02 & 03 & 04 & 05 & 06 & 07 & 08 & 09 & 10 & 11 & 12 & $\begin{array}{c}\text { Tot } \\
\text { al }\end{array}$ \\
\hline 2017 & 41,3 & 53,5 & 94,6 & 71,7 & 91,4 & 10,2 & 92,8 & 10,4 & 12,4 & 12,5 & 14,8 & 17,6 & 12,2 \\
\hline 2018 & 82,0 & 81,0 & $\begin{array}{c}14,1 \\
0\end{array}$ & 12,8 & $\begin{array}{c}15,9 \\
6\end{array}$ & 16,8 & 14,4 & 17,5 & 20,6 & 21,4 & 23,7 & 28,6 & 20,1 \\
\hline 2019 & $\begin{array}{c}159 \\
4\end{array}$ & $\begin{array}{c}119 \\
5\end{array}$ & $\begin{array}{c}224 \\
3\end{array}$ & $\begin{array}{c}166 \\
2\end{array}$ & $\begin{array}{c}179 \\
2\end{array}$ & $\begin{array}{c}264 \\
5\end{array}$ & $\begin{array}{c}157 \\
1\end{array}$ & $\begin{array}{c}160 \\
1\end{array}$ & $\begin{array}{c}183 \\
3\end{array}$ & $\begin{array}{c}149 \\
5\end{array}$ & $\begin{array}{c}176 \\
5\end{array}$ & $\begin{array}{c}319 \\
8\end{array}$ & 22,6 \\
\hline
\end{tabular}


Analysis of the strategies of the largest car manufacturers at the present stage has shown that almost all companies include projects for the production of non-electric and hybrid vehicles as priorities.

For example, one of the world leaders in the global automotive industry, the BMW Group, intends to become a leader in autonomous driving technology and driver assistance functions by introducing new electric and hybrid models. Sales of the company's electrified vehicles electric vehicles and hybrids - grew immediately by $65 \%$ in 2017 , reaching 103,080 units.

In July 2019, representatives of the company's top management announced ambitious goals for the electrification of their car fleet:

- in 2021 - to double sales of electric models and hybrids;

- by 2023 - two years earlier than planned - to increase to 25 electrified models on the market. More than half will be fully electric.

- by 2025 , sales of electrified vehicles will grow by an average of over 30 percent per year.

There is growing interest in innovative solutions for electric vehicle technology and auto giant Volkswagen AG, which is about to change plans for the development of electric vehicle technology. This is due to the tightening of standards for carbon dioxide emissions by the EU authorities. If earlier the concern planned to invest 30 million euros in the development of technologies for electric vehicles by 2022 and in 10 years to produce 50 models of electric vehicles, now the company intends to significantly increase the production of new models of electric vehicles by 2028 by increasing their number to 70 and increasing the number assembled electric cars from 15 million to 22 million units. The concern entered the TOP-10 in terms of sales among electric car models in 2020 (Table 2).

Table 2. Top sellers among electric car models in 2020 (in thousands of rounded units)

\begin{tabular}{|l|r|}
\hline Tesla Model 3 & 365 \\
\hline Wuling HongCuang Mini EV & 119 \\
\hline Renault Zoe & 100 \\
\hline Tesla Model Y & 80 \\
\hline Hyundai Kona Electric & 65 \\
\hline Volksvagen ID.3 & 57 \\
\hline Nissan Leaf & 56 \\
\hline SAIC Baojun E-Series & 48 \\
\hline Audi e-Tron & 48 \\
\hline Great Wall ORA R1/ Black Cat & 47 \\
\hline
\end{tabular}

From the data presented, it can be seen that the Tesla Model 3 model takes a confident leading position. In 2017, she was ranked 106th in the ranking.

Particular attention should be paid to the strategic programs of car manufacturers in the Asian region. For example, China is the largest car market in the world. New energy vehicle sales have continued to grow at a rapid pace over the years. The country was in third place among the countries with the largest share of electric vehicles in the global transport market, its share was about $1 \%$. The leading positions here were occupied by such companies as BAIC, Chery, Geely, JAC. But according to the results of the "pre-crisis" 2019 and 2020, the year of the pandemic, one can notice a significant decline in sales.

Fig. 3 shows the dynamics of sales of electric vehicles and plug-in hybrids of 14 Chinese companies in 2018-2020, which were leaders in this area in 2018. 


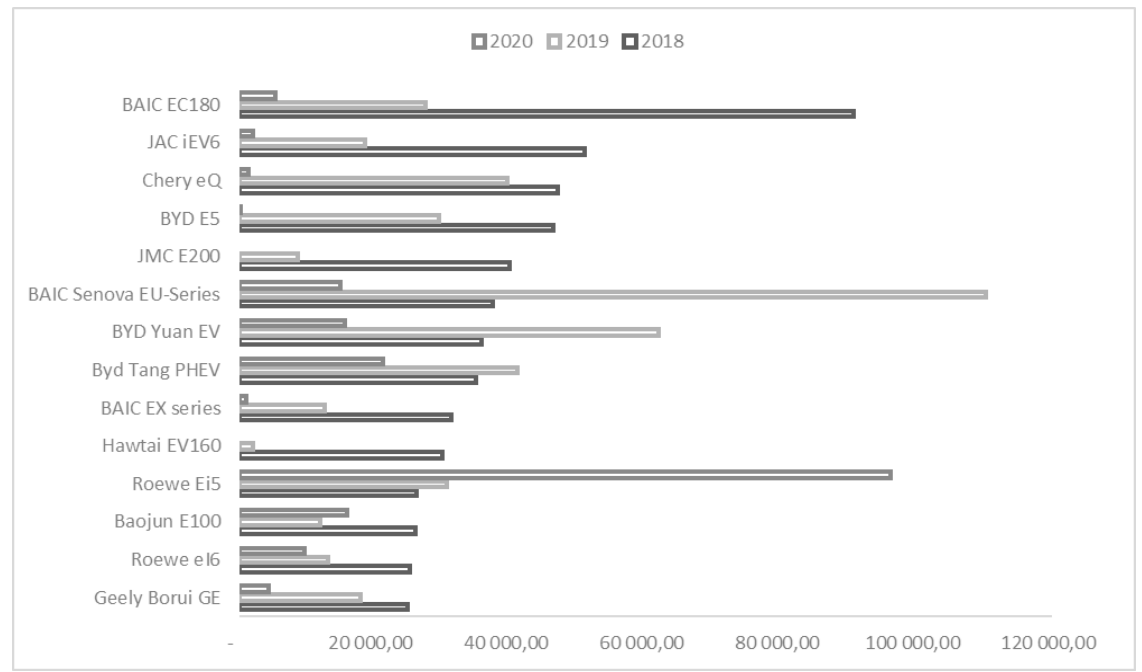

Fig. 3. Comparative dynamics of sales of passenger cars and passenger electric vehicles for 2012-2020

Norway is currently the world leader in the consumption of electrically driven vehicles (about 40\%). The vice-leader in the use of electrically driven vehicles is Sweden with an indicator of more than $5 \%$.

The past tough year of the COVID-19 pandemic has proven extremely successful for the electric vehicle market.

EV-Volumes has released preliminary sales figures for BEV (battery electric vehicles) + PHEV (Plug-in hybrid electric vehicles), which are classified as plug-in.

If in the "pre-crisis" 2019, sales of electric vehicles practically did not increase, and according to some estimates, there was even a decrease in volumes in key markets - in the PRC and the USA, then in 2020, despite all the quarantines, an impressive increase in sales of electric vehicles was recorded.

Thus, at the end of 2020 , BEV + PHEV sales grew by $43 \%$ compared to 2019 , and their share in global sales exceeded $4 \%$.

The growth of the electric vehicle market in Europe for the year was $137 \%(!)$, and sales of BEV + PHEV reached 1.4 million units and this is in the context of the crisis in the automotive market as a whole, where sales fell by $20 \%$. For the first time since 2015, sales of electric vehicles in Europe exceeded sales in China.

The share of electric cars in European sales reached 10.2\%, while in China the share of NEV was $5.5 \%$ (5.1\% in 2019).

Germany, where not so long ago electric cars were not popular, came to the second place after China in terms of sales.

\section{Russian electric vehicle market: state and problems}

Russian electric vehicle market: state and problems Russia is one of the largest players in the global car consumption market, but, unfortunately, has recently lost its position among manufacturers.

The first serial Russian car on electric traction was produced by AvtoVAZ - Lada Ellada. 10 million euros were invested in the development of the model. In this case, the cost of the production model is 1,250,000 rubles. In addition, AvtoVAZ has developed and launched another electric model - Vesta EV. 
One of the largest manufacturers of commercial vehicles in Russia, GAZ Group, produces a serial Russian electric car - Gazelle Next Electro.

In general, electric modes of transport in the Russian Federation have good prospects. In 2020, 687 electric vehicles were sold in the country in absolute terms, compared with 353 in 2019.

In the regional rating of new electric vehicles, Moscow is the leader (240 units) for 2020, followed by St. Petersburg ( 69 units) and the third position is the Moscow region (60 units). The Krasnodar Territory is the leader among non-capital regions (36 units), followed by the Primorsky Territory (31 units), the Sverdlovsk Region (21 units), and the Novosibirsk Region (20 units). More than 10 (pcs.) Electric cars were purchased in 4 constituent entities of the Russian Federation: Perm Territory, Irkutsk, Chelyabinsk and Tyumen regions.

Today, the main limiting factor is the price of electric vehicles, which is still too high. In addition, it should be noted that an insufficiently developed network of electric filling stations plays a role in the development of electric transport.

Namely, it depends on the rate of development of this infrastructure when Russia will switch to electric vehicles.

For comparison, in the United States there are now more than 50000 charging stations, in Amsterdam there are about 20000 charging stations. While in Russia, according to the plugshare.com service, which marks all charging points for electric vehicles, today there are less than 1 000. According to the forecasts of the Association for the Development of Electric, Unmanned and Connected Transport and Infrastructure (AETI), in the coming years the number of charging stations in Russia should increase two to three times. Russian developers are actively installing charging stations for electric vehicles in the construction of housing and shopping and entertainment centers.

Taking into account the fact that the number of electric cars in the country is growing steadily, there is an urgent need to create a regulatory document that would oblige construction and management companies to ensure the availability of electric charging stations in the yards of apartment buildings, shopping centers, hotels, etc.

So, for example, in St. Petersburg on January 1, 2019, a local regulatory act began to operate, obliging developers to install charging stations in new residential complexes.

If we talk about what the Russian fleet of electric vehicles is, then according to the analytical agency AUTOSTAT, 10836 electric cars were registered in the Russian fleet of passenger cars as of January 1, 2021. At the beginning of the year, the electric car market is represented in our country by 18 models of 14 different brands.

About $80 \%$ of all electric cars registered on the territory of the Russian Federation belong to one model - Nissan Leaf, which has a fleet of more than 9 thousand units. The second place in the rating is taken by Tesla (models 3, S, X, Y - about 700 units in total). This is followed by the Mitsubishi i-MiEV (400 units).

\section{Conclusions}

Based on the study, it was revealed that the production of electric and hybrid vehicles, after many years of neglect, has now become one of the most important areas of strategic planning both at the global and Russian levels in the automotive industry.

It was revealed that all the theoretical positions of K. Andrews, M. Porter, G. Hamel, K. Prahalad on obtaining competitive advantages in the development of long-term strategies in the automotive industry have the right to be directly applied. As an example, the main strategic directions of development of both leading Western European, Chinese, and Russian companies - car manufacturers are considered. A stable growth in demand for cars that do not use internal combustion engines for both personal and commercial use has been revealed. 
In the course of the study, bottlenecks were identified that hinder the spread of electric vehicles, in particular, in the territory of the Russian Federation, and recommendations were given to solve this problem.

\section{References}

1. V. V. Iosifov, E. E. Bobylyov, Financial Analytics: Problems and solutions, 10-11, 1273 (2017)

2. A. V. Pas'ko, E-Management, 2, 16 (2019)

3. D. A. Plexanov, S. M. Zaverskij, N. M. Churkina, Russian Entrepreneurship, 16(24), 4375 (2015)

4. M. Porter, Competitive strategy, 301 (M.: Al’pina Biznes-buk, 2013)

5. K. K. Praxalad, G. Xe'mel, Core competencies of the Corporation, 117 (SPb: Piter, 2011)

6. S. V. Ratner, S. S. Maslova, Finance and Credit, 23(22), 1281 (2017)

7. Boucar Diouf, Ramchandra Pode, Financial Analytics: Problems and solutions, 10-12, 1380 (2017)

8. T. S. Remizova, Financial Analytics: Problems and solutions, 10-12, 1380 (2017)

9. K. O. Tarxanovskij, Accounting in budget and non-profit organizations, 17, 34 (2017)

10. E. D. Chirkina, Management of electronic economic systems, 8, 21 (2017)

11. K. E’ndryus, Corporate strategy Concept, 252 (2010) 